\title{
WATER QUALITY MONITORING OVER FINGER LAKES REGION USING SENTINEL-2 IMAGERY ON GOOGLE EARTH ENGINE CLOUD COMPUTING PLATFORM
}

\author{
Rabia Munsaf Khan ${ }^{1 *}$, Bahram Salehi ${ }^{1}$, Masoud Mahdianpari ${ }^{2}$, Fariba Mohammadimanesh ${ }^{2}$ \\ ${ }^{1}$ Department of Environmental Resources Engineering, State University of New York - College of Environmental Science and \\ Forestry (ESF), NY 13210, USA \\ ${ }^{2}$ C-CORE and Department of Electrical and Computer Engineering, Memorial University of Newfoundland, St. John's, NL A1B \\ $3 \mathrm{X} 5$, Canada
}

KEYWORDS: Google Earth Engine, Finger Lakes, Sentinel 2, Sediment loading, Water quality

\begin{abstract}
:
Surface water quality is degrading continuously both due to natural and anthropogenic causes. There are several indicators of water quality, among which sediment loading is mainly determined by turbidity. Normalized Difference Water Index (NDWI) is one indirect measure of sediments present in water. This study focuses on detecting and monitoring sediments through NDWI over the Finger Lakes region, New York. Time series analysis is performed using Sentinel 2 imagery on the Google Earth Engine (GEE) platform. Finger Lakes region holds high socio-economic value because of tourism, water-based recreation, industry, and agriculture sector. The deteriorating water quality within the Finger Lake region has been reported based on ground sampling techniques. This study takes advantage of a cloud computing platform and medium resolution atmospherically corrected satellite imagery to detect and analyse water quality through sediment detection. In addition, precipitation data is used to understand the underlying cause of sediment increase. The results demonstrate the amount of sediments is greater in the early spring and summer months compared to other seasons. This can be due to the agricultural runoff from the nearing areas as a result of high precipitation. The results confirm the necessity for monitoring the quality of these lakes and understanding the underlying causes, which are beneficial for all the stakeholders to devise appropriate policies and strategies for timely preservation of the water quality.
\end{abstract}

\section{INTRODUCTION}

Surface water is very crucial for the survival of life on Earth and is used primarily for drinking and agricultural purposes (Acharya et al., 2019). Unfortunately, surface water is facing serious pollution issues due to various natural and anthropogenic causes (Kulkarni, 2011; Wirabumi et al., 2020; Yunus et al., 2020).

Many indicators can determine water quality; however, many studies have used turbidity as a measure of overall water quality. Turbidity of water bodies results from suspended particles in the water caused by sediment loading, agriculture runoff, sewage disposals and other pollutants and metals. Sediment loading is mostly caused by runoff events after heavy rainfall. Turbidity causes cloudiness of the water and can be considered as a key measure for water quality. As a result, poor water quality can lead to expensive water treatment plants and can have an impact on habitat quality. Furthermore, higher turbidity may cause health issues such as gastrointestinal diseases (Kulkarni, 2011). It is important to monitor water quality of inland lakes as these are important for socio-economic development, biodiversity conservation, and tourism. Thus, the spatiotemporal distribution of sediment loading is particularly important for understanding and monitoring water quality in inland water bodies.

Inland lakes, such as Finger Lakes, which comprise of a total of 11 lakes, attract tourists due to their natural beauty. Finger Lakes annually attracts over 22 million tourists, resulting in the generation of $\$ 2$ billion revenue. Numerous studies have carried out to detect and monitor water quality in various Finger Lakes. For example, a survey conducted in 2005 included Canandaigua, Owasco, Cayuga, Seneca, Keuka and Skaneateles lakes as they contain 98\% water of total Finger Lakes (Halfman et al., 2006). Later study conducted in 2008 also included Otisco lake in their analysis. Several other studies were also carried out in this region (Halfman et al., 2009) focusing on various water quality parameters, including turbidity. Although these actions are of particular importance for water quality assessment within the region, they are resource-intensive and, as such, are limited to small geographic areas.

Satellite Earth Observation (EO) data can be used to address the limitations of conventional water quality techniques by taking synoptic view of landscape over a large geographic region. This makes them advantageous for long-term studies using time series analysis compared to in situ investigation. Several studies reported the success of mapping and monitoring inland water quality for enhancing the regional assessment (Abdullah et al., 2016; Morel \& Bélanger, 2006; Ticman et al., 2018).

Depending upon the size of study area, different satellites and sensors are used, such as Moderate Resolution Imaging Spectroradiometer (MODIS) (Zhang et al., 2005) , Landsat (Ticman et al., 2018) and Sentinel 2 (Bonansea et al., 2019). Most of the studies related to water quality monitoring, utilize the visible and near infra-red (NIR) spectral bands as higher correlation is observed between spectral values from these bands and in-situ measurements (Wirabumi et al., 2020). Furthermore, the infra-red wavelength can be used to determine the amount of sediments suspended in the water bodies (Jensen, 2009). Although several methods have been suggested in the literature for measuring turbidity ranging from ground-based methods such as Secchi disk depth (Su et al., 2008) to developing empirical algorithms (Bustamante et al., 2009), yet water quality indices

*Corresponding Author: rkhan06@syr.edu 
are preferred due to their simplicity and low computational cost (Acharya et al., 2019). Furthermore, cloud-based computing platforms such as Google Earth Engine (GEE) aids in processing of large-scale satellite imagery while utilizing less resources (Markert et al., 2018; Tamiminia et al., 2020).

In this study, a simple water index is used to determine sediment loading and analyse time series to assess the water quality for Finger Lakes region in New York, USA. Furthermore, water quality data is compared to precipitation data to visualize its effects. This study is carried out using satellite imagery from Sentinel-2 using GEE as the computing platform. To the best of our knowledge, this is the first attempt to monitor water quality using Sentinel 2 imagery over Finger Lakes on the GEE platform.

\section{MATERIAL AND METHODS}

\subsection{Study Area}

As shown in Figure 1, the study area is comprised of Finger Lakes region in New York State, consisting of 11 lakes, namely Otisco, Skaneateles, Owasco, Cayuga, Seneca, Keuka, Canandaigua, Honeoye, Canadice, Hemlock and Conesus. These lakes are long and narrow and run almost north to south, thus giving them the name of "finger" lakes. Although none of them is greater than 3.5 miles in width, however, their length varies from 3 miles to 38 miles. These lakes are spread over 14 counties, containing about 8.1 trillion litres of water supplying quality water to neighbouring cities and surrounding communities Specifically, the Skaneateles and Otisco Lake provide drinking water to the city of Syracuse. Similarly, for Rochester, the providing lakes are Canadice and Hamlock. The total withdrawals can reach up 190 million gallons of water per day (Halfman et al., 2006).

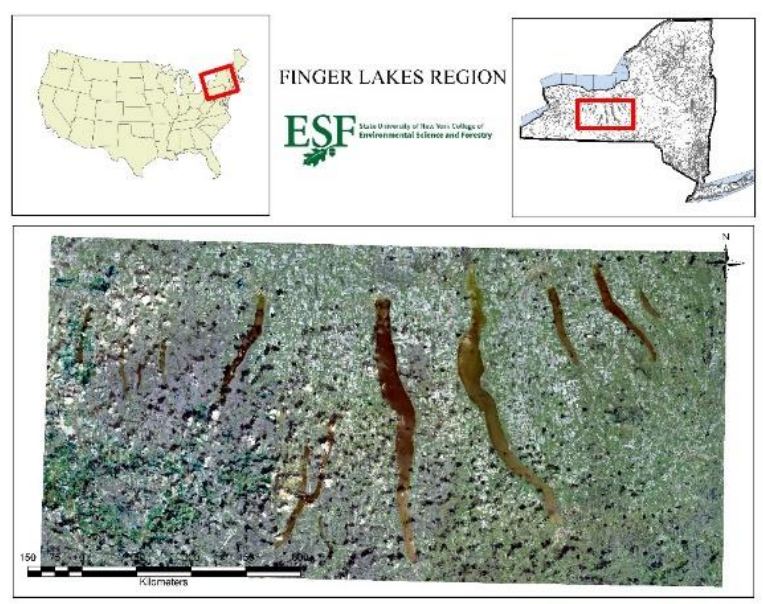

Figure 1: Study Area Showing Finger Lakes

The watershed of these lakes is dominated by agriculture, forest and shrubland, however urban settlement can also be seen increasingly over the past years due to tourism and recreational activities. Specifically, the agricultural land covers about $45 \%$ of these watersheds, followed by forests covering up to $38 \%$ and lastly the urban areas comprise of only $4 \%$ of total watersheds (Halfman et al., 2009). As the land use is majorly agriculture, the biggest contributor of deteriorating water quality is the sediment runoff from the agricultural lands. The sediments can cause nutrient loading stimulating algal bloom which can reduce the lake clarity and quality. In particular, the detailed analysis is carried out for two lakes, namely Seneca and Owasco, given their worst water quality (Halfman et al., 2006). Furthermore, these were in proximity with a ground based meteorological station, making them advantageous compared to other lakes for correlating precipitation data.

\subsection{Satellite Imagery}

The Sentinel-2 mission consists of two satellites, namely Sentinel-2A and Sentinel-2B, launched in 2015 and 2017 respectively, providing multispectral optical imagery with a spatial resolution of $10 \mathrm{~m}, 20 \mathrm{~m}$, and $60 \mathrm{~m}$. In this study, level $2 \mathrm{~A}$ data is used for 2019 and 2020 over Finger Lakes region. The satellite imagery is accessed and processed using the GEE platform.

\subsection{Precipitation Data}

Precipitation data for two stations were downloaded from NOAA's National Centers for Environmental Observation website (https://gis.ncdc.noaa.gov). Daily precipitation data for year 2019 and 2020 were downloaded for Auburn station (42.9327, -76.5447) corresponding to Owasco lake and Geneva station $(42.8766,-77.0307)$ corresponding to Seneca lake.

\subsection{Methodology}

The advantage of using GEE lies in the readily available data and cloud server processing without the need of downloading gigabytes of imagery. In this study, Sentinel 2 level 2A imagery for 2019-2020 over Finger Lakes region was analysed for hotspot detection and temporal progression of sediment loading. For this purpose, Normalized Difference Water Index (NDWI) was used to separate the sedimented regions from clear water. The formula for NDWI is as follows:

$$
\mathrm{NDWI}=\frac{\text { Green }-\mathrm{NIR}}{\text { Green+NIR }}
$$

where Green corresponds to the band $3(560 \mathrm{~nm})$ and NIR corresponds to the band $8(842 \mathrm{~nm})$ of Sentinel imagery. NDWI can be extracted in multiple ways $(\mathrm{Xu}, 2006)$; however, the original index is used in this study because of two reasons. First, it includes both bands with $10 \mathrm{~m}$ spatial resolution hence increasing the spatial resolution; second, the water quality parameters are better correlated with visible and NIR spectral bands.

For detailed analysis, time series charts were generated using GEE and compared with the precipitation data for correlation.

\section{RESULTS AND DISCUSSION}

Firstly, NDWI was calculated to distinguish sedimented waters from clear waters on a broader scale to detect hotspots for sediment loading, which is one of the major causes for turbidity. The results for NDWI over Finger Lakes region for May 2019 can be seen from Figure 2 .

It clearly indicates the disturbance in water due to sediment loading in all the lakes. The colours blue and green corresponds to values less than zero, hence are an indication of non-water bodies. The values between zero to one represent water bodies where closer to one is an indication of pure water and closer to zero represents sedimented water.

For further analysis, two study areas were chosen based on previous literature and their proximity to the nearest ground based meteorological station shown in light blue dots in Figure 3. In both study sites, high concentration of sediments can clearly be seen represented in tones of red whereas the clear water is represented in the tones of yellow. Although in the whole Finger Lakes region, there are many other hotspots as well but only two 
were chosen due to the smaller scope of this study and literature recommendation (Makarewicz et al., 2007).

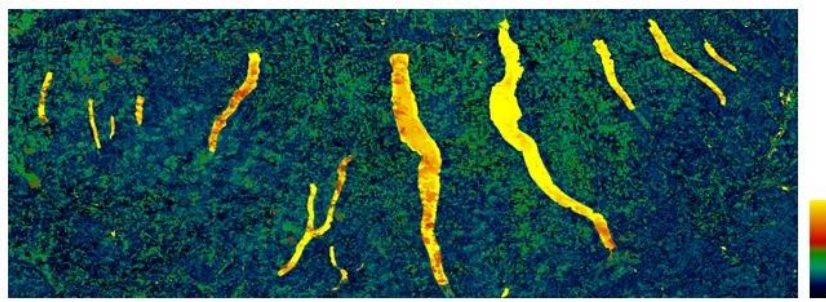

Figure 2: NDWI values ranging from Blue (-1) to Yellow (1) for the Finger Lakes Region

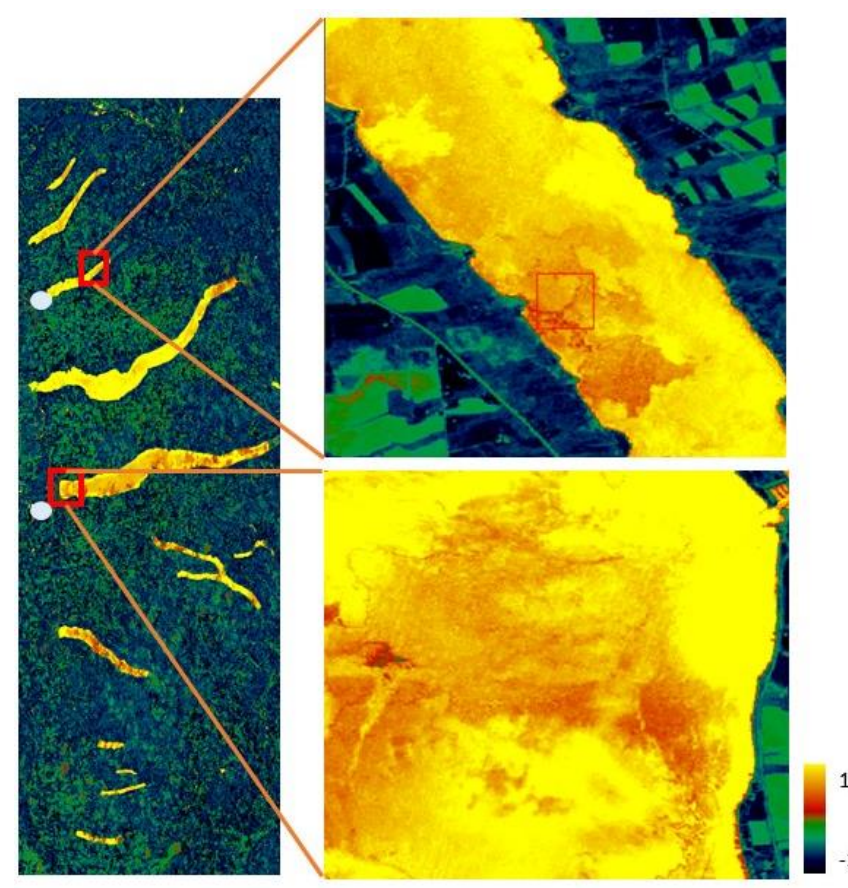

Figure 3: Two highlighted regions from the study area. Top: Owasco Lake. Bottom: Seneca Lake

As single imagery is unable to determine the seasonal changes, time series charts were generated for 2019-2020 for these two sites in GEE. For the study sites near Geneva station and Auburn stations, the charts can be visualized in Figure 4 and Figure 5, respectively.

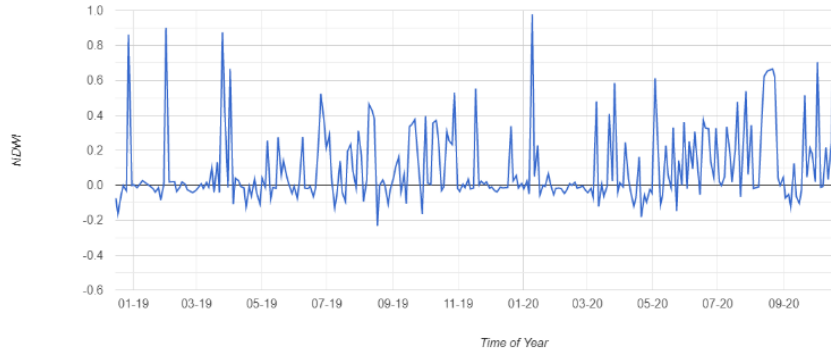

Figure 4: Time Series of NDWI for Owasco Lake

Generally, it can be seen from both graphs that the NDWI values are higher for winter season as compared to summer. This can be associated to the freezing of lakes in winters and the surface reflectance is majorly coming from the water itself only. Also, the values of NDWI are higher in 2020 as compared to 2019 which indicates a decrease in sediment loading. This is in contrast with the general assumption that sediment loading is increasing over time; however, in 2020 due to COVID lockdown a decrease in sediment loading and hence water turbidity is seen in other studies as well (Yunus et al., 2020).

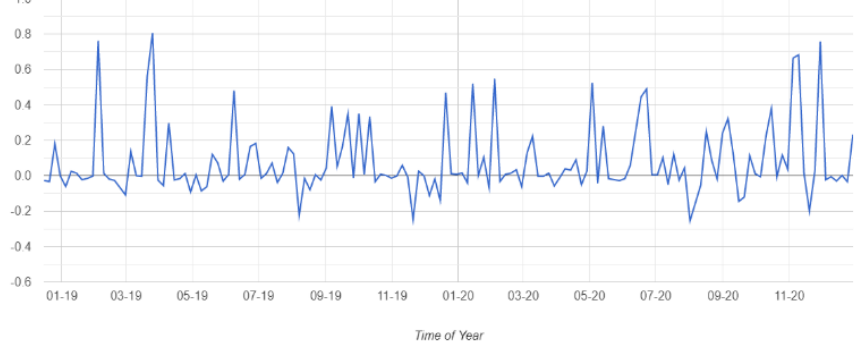

Figure 5: Time Series of NDWI for Seneca Lake

\begin{tabular}{|l|l|l|l|l|}
\hline \multirow{2}{*}{} & \multicolumn{2}{|l|}{ Geneva - Rainfall (mm) } & \multicolumn{2}{l|}{ Auburn - Rainfall (mm) } \\
\cline { 2 - 5 } & 2019 & 2020 & 2019 & \multicolumn{2}{|c|}{2020} \\
\hline Jan & 2.25 & 1.68 & 127.4 & 85.2 \\
Feb & 1.94 & 2.49 & 71.8 & 88.6 \\
Mar & 0.72 & 2.12 & 44.2 & 84.4 \\
Apr & 2.2 & 1.37 & 86.7 & 74.9 \\
May & 5.5 & 2.89 & 121.2 & 93.9 \\
Jun & 4.46 & 1.9 & 129.6 & 40.7 \\
Jul & 2.87 & 5.27 & 160.1 & 207 \\
Aug & 5.82 & 2.38 & 152.7 & 75.8 \\
Sep & 2.68 & 1.96 & 78.3 & 44 \\
Oct & 4.73 & 3.19 & 125.6 & 97.6 \\
Nov & 1.87 & 2.88 & 75.7 & 64.2 \\
Dec & 2.76 & 1.45 & 108.6 & 101.6 \\
\hline
\end{tabular}

Table 1: Monthly Total Precipitation Values for Two Stations

The total precipitation values for each month for two study sites are summarized in Table 1. Surprisingly, the amount of rainfall differs substantially among two study sites as evident from the table. Nonetheless, there are certain patterns that can be observed in both cases. First, the amount of rainfall is generally high in both Summer and Winter season. Secondly, in 2020 the amount of rainfall has decreased slightly as compared to 2019 .

As observed from Figure 4 and Figure 5 that the values of NDWI are generally lower in the months of Spring and Summer. This can be associated to a higher amount of rainfall and thus greater runoff. Notably, the precipitation values are also higher in winters, but the NDWI is also greater suggesting the presence of pure water body. This can be associated with the fact that in winters the lakes are frozen. Secondly, as mentioned before, the watershed majorly comprises of agricultural land and that plays an important role in the spring and early summer seasons. Specifically, the runoff is greater because at that time the agricultural fields are tilled for plantation, hence the amount of bare soil is increased. Furthermore, due to tilling, the soil is loose and contributes to the increased sedimentation loading in the lakes. This was verified by a previous study in which the correlation between water quality ranking and agricultural runoff came out to be $98 \%$ (Halfman et al., 2009).

Also, the previous studies confirm that the water quality in both lakes have decreased from oligotrophic to mesotrophic (Halfman et al., 2006; Makarewicz et al., 2007). In this study, only twoyear data were utilized due to archive limitation of atmospherically corrected Sentinel 2 data on GEE. However, this 
study can be extended for a longer period of time using Landsat data. Although the spatial resolution of Landsat is $30 \mathrm{~m}$, it can be increased by pan sharpening or data fusion with Sentinel 2 . Another alternative is to use high spatial and temporal resolution data provided by PlanetScope (Maciel et al., 2020; Musfiroh et al., 2020), which will help in better understanding of spatiotemporal patterns for sediment loading in Finger lakes region. In this study, only the effect of precipitation was analysed; however, for future studies the impact of other factors such as wastewater treatment facilities near the study areas can also be examined. These lakes are essential for the socio-economic structure of this region as they support tourism and recreation. Hence, monitoring the quality of these lakes and understanding the underlying causes would be beneficial for all the stakeholders to devise appropriate policies and strategies for timely preservation of the water quality.

\section{CONCLUSION}

In this study, NDWI time series analysis was used to detect sedimented waters in the Finger Lakes region using Sentinel 2 atmospherically corrected imagery on the GEE platform. In addition, the effect of precipitation was analysed for Owasco and Seneca Lake. The results revealed that the amount of sediments is greater in early spring and summer months. This can be associated with the presence of agricultural land around the study areas. In these months, the amount of bare soil is greater due to plantation season, which increases the sediment runoff. However, an increasing trend could not be visualized as our data were limited to two years; however, the literature confirmed that the water quality is deteriorating rapidly in both lakes. The use of a longer time period and higher temporal frequency data is suggested for future research. This type of study is of particular importance, as it detects and monitor the water quality on a regular basis utilizing minimum resources. This is critical because once the water body is stressed, it takes decades to restore it to its original state.

\section{REFERENCES}

Abdullah, H. S. A., Mahdi, M. S. M., \& Ibrahim, H. M. I. (2016). Water Quality Assessment Models for Dokan Lake Using Landsat 8 OLI Satellite Images. Journal of Zankoy Sulaimani - Part A, 19(3\&4), 25-42. https://doi.org/10.17656/jzs.10630

Acharya, T. D., Subedi, A., Huang, H., \& Lee, D. H. (2019). Application of water indices in surface water change detection using Landsat imagery in Nepal. Sensors and Materials, 31(5), 1429-1447. https://doi.org/10.18494/SAM.2019.2264

Bonansea, M., Ledesma, M., Bazán, R., Ferral, A., German, A., O’Mill, P., Rodriguez, C., \& Pinotti, L. (2019). Evaluating the feasibility of using Sentinel-2 imagery for water clarity assessment in a reservoir. Journal of South American Earth Sciences, 95(July), 102265. https://doi.org/10.1016/j.jsames.2019.102265

Bustamante, J., Pacios, F., Díaz-Delgado, R., \& Aragonés, D. (2009). Predictive models of turbidity and water depth in the Doñana marshes using Landsat TM and ETM+ images. Journal of Environmental Management, 90(7), 22192225.

https://doi.org/https://doi.org/10.1016/j.jenvman.2007.08. 021

Halfman, J. D., Colleges, W. S., \& Colleges, W. S. (2006).
Finger Lake Water Quality, A Preliminary Report: 2005 1 Finger Lakes Institute, Hobart \& William Smith Colleges. 1-15.

Halfman, J. D., Colleges, W. S., \& Colleges, W. S. (2009). WATER QUALITY OF THE FINGER LAKES, NEW YORK: 2005 - 2008. 2005-2008.

Jensen, J. R. (2009). Remote sensing of the environment: An earth resource perspective 2/e. Pearson Education India.

Kulkarni, A. (2011). Water quality retrieval from landsat TM imagery. Procedia Computer Science, 6, 475-480. https://doi.org/10.1016/j.procs.2011.08.088

Maciel, D. A., Novo, E. M. L. D. M., Barbosa, C. C. F., Martins, V. S., Flores Júnior, R., Oliveira, A. H., Sander De Carvalho, L. A., \& Lobo, F. D. L. (2020). Evaluating the potential of CubeSats for remote sensing reflectance retrieval over inland waters. International Journal of Remote Sensing, 41(7), 2807-2817. https://doi.org/10.1080/2150704X.2019.1697003

Makarewicz, J. C., White, D. J., \& Lewis, T. W. (2007). Water Quality of the North End of Seneca Lake: 1991-2006. 1991-2006.

http://digitalcommons.brockport.edu/tech_rep/15

Markert, K. N., Schmidt, C. M., Griffin, R. E., Flores, A. I., Poortinga, A., Saah, D. S., Muench, R. E., Clinton, N. E., Chishtie, F., Kityuttachai, K., Someth, P., Anderson, E. R., Aekakkararungroj, A., \& Ganz, D. J. (2018). Historical and operational monitoring of surface sediments in the Lower Mekong Basin using Landsat and Google Earth Engine cloud computing. Remote Sensing, 10(6), 1-19. https://doi.org/10.3390/rs10060909

Morel, A., \& Bélanger, S. (2006). Improved detection of turbid waters from ocean color sensors information. Remote Sensing of Environment, 102(3), 237-249. https://doi.org/https://doi.org/10.1016/j.rse.2006.01.022

Musfiroh, Z., Ridwansyah, I., \& Murti, S. H. (2020). The application of PlanetScope imagery to map out the trophic state of Cirata Reservoir, West Java. IOP Conference Series: Earth and Environmental Science, 535(1). https://doi.org/10.1088/1755-1315/535/1/012032

Su, Y.-F., Liou, J.-J., Hou, J.-C., Hung, W.-C., Hsu, S.-M., Lien, Y.-T., Su, M.-D., Cheng, K.-S., \& Wang, Y.-F. (2008). A Multivariate Model for Coastal Water Quality Mapping Using Satellite Remote Sensing Images. SENSORS, 8(10), 6321-6339. https://doi.org/10.3390/s8106321

Tamiminia, H., Salehi, B., Mahdianpari, M., Quackenbush, L., Adeli, S., \& Brisco, B. (2020). Google Earth Engine for geo-big data applications: A meta-analysis and systematic review. ISPRS Journal of Photogrammetry and Remote Sensing, 164(January), 152-170. https://doi.org/10.1016/j.isprsjprs.2020.04.001

Ticman, K. D. V., Medina, J. M., Gubatanga, E. V., Jalbuena, R. L., Santos, J. A. S., Sta Ana, R. R. C., \& Blanco, A. C. (2018). Assessment of Landsat 8-based indices for water quality parameter estimation in Laguna de Bay, Philippines. Proceedings - 39th Asian Conference on Remote Sensing: Remote Sensing Enabling Prosperity, ACRS 2018, 2, 1022-1027.

Wirabumi, P., Wicaksono, P., Kamal, M., Ridwansyah, I., 
Subehi, L., \& Dianto, A. (2020). Spatial Distribution Analysis of Total Suspended Solid (TSS) using PlanetScope Data in Menjer Lake, Wonosobo Regency. Journal of Applied Geospatial Information, 4(1), 289297. https://doi.org/10.30871/jagi.v4i1.1853

Yunus, A. P., Masago, Y., \& Hijioka, Y. (2020). COVID-19 and surface water quality: Improved lake water quality during the lockdown. Science of the Total Environment, 731, 139012. https://doi.org/10.1016/j.scitotenv.2020.139012

Zhang, X., Yang, D., Zhang, X., Wang, D., Li, S., \& Pan, D. (2005). Pre-operational monitor system of large inland lake water quality with MODIS imagery. Proceedings of SPIE - The International Society for Optical Engineering, 5977. https://doi.org/10.1117/12.627386 